\title{
General Psychiatry Impact of clinical posting in psychiatry on the attitudes towards psychiatry and mental illness in undergraduate medical students
}

\author{
Rishi Desai, ${ }^{\oplus}$ Bharat Panchal, Ashok Vala, Imran Jahangirali Ratnani, \\ Sneha Vadher, Pushpa Khania
}

To cite: Desai $R$, Panchal $B$, Vala A, et al. Impact of clinical posting in psychiatry on the attitudes towards psychiatry and mental illness in undergraduate medical

students. General Psychiatry 2019;32:e100072. doi:10.1136/ gpsych-2019-100072

Received 28 March 2019

Revised 26 April 2019

Accepted 29 May 2019

\section{Check for updates}

(c) Author(s) (or their employer(s)) 2019. Re-use permitted under CC BY-NC. No commercial re-use. See rights and permissions. Published by BMJ.

Department of Psychiatry, Government Medical College, Bhavnagar, India

Correspondence to Dr Sneha Vadher; sneha.vadher@yahoo.com

\section{ABSTRACT}

Background A major public health problem around the world today is mental illness. Although there are several studies on the topic, it is rarely conducted in the context like the current study.

Aims This study aims to find out the attitudes of medical students towards psychiatry and mental illness as a clinical medicine major and evaluate the effects of clinical posting on their attitudes towards psychiatry and mental illness.

Methods This is a longitudinal study of 6 months' duration conducted with students in their fifth semester of medical college in Western India during the academic year of 2016-2017. The participants were assessed by pro forma containing demographic details, and the questionnaires-Attitude Towards Psychiatry-30 items (ATP-30) scale and Mental IIIness Clinician's Attitude (MICA) scale, which were presented to the students at the beginning and at the end of their psychiatry clinical posting. The statistical analysis was done with GraphPad, InStat V.3.06. A p value $<0.05$ was considered statistically significant.

Results The students' attitudes towards psychiatry were neutral at the beginning of the psychiatry clinical posting, and improved significantly at the end of the posting on both scales: ATP-30 $(p=0.002)$ and MICA $(p=0.048)$. The students became more positive towards the subject and mental illness in general, negative attitudes also reduced but the change was not statistically significant $(p=0.058)$. We found significant improvement in students' thinking towards being a psychiatrist in the future post-term $(p=0.0002)$. The changes in attitude in terms of gender were equivocal, with an increase in positive attitude and reduction in negative attitude post-term in both sexes. Conclusion Psychiatry clinical posting aids in cultivating positive attitude towards psychiatry and mental illness and reduces the stigma associated with the students of this major and psychiatric patients.

\section{INTRODUCTION}

A major public health problem around the world today is mental illness. ${ }^{1}$ It is common, disabling and causing conditions that impact negatively a person's quality of life. ${ }^{2}$ It makes a person less productive and spoils his meaningful interactions with himself, his family and the world around him. ${ }^{3}$ To add to their woes, people with mental illness are subjected to stigmatisation, marginalisation and discrimination. ${ }^{4}$ The prevalence and incidence of mental illness are predicted to rise in the coming years.

In order to ensure the well-being and integration of people with mental illness, young, enthusiastic and open-minded doctors are the need of the hour. However, a systemic review revealed that while medical students' attitudes towards psychiatry are generally positive, psychiatry as a potential career choice is unpopular. $^{5}$

Attitude is defined by Rezler as 'an emotionally linked, learnt belief around an object or situation predisposing one to respond in some preferential manner. ${ }^{6}$ It is the attitudes towards psychiatry and mental illness among undergraduate medical students that determine the future course of action in this field. In 1982, Burra and colleagues who validated the Attitude Towards Psychiatry-30 items(ATP-30) scale found that the positive attitude changes towards psychiatry in medical students in third and fourth years of their training were related to their exposure to psychiatry. Changes in students' attitude were proportionate to their exposure to patients and subjects. ${ }^{7}$

The negative attitude towards psychiatry among medical students contributes to low excitement in terms of recruitment in the field. ${ }^{8-12}$ Thus, the changes in the attitude of medical students towards psychiatry and mental illness can contribute to altering public views about psychiatry.

Although there are several studies on this topic, they are rarely conducted in a context like this study. We have come across only one such study, and it was cross sectional. Thus, 
it is paramount to undertake studies that evaluate the impact of clinical posting in psychiatry on undergraduate medical students on a longitudinal basis in order to further generate interest in the field for young doctors.

The female proportion in psychiatry is low compared with other majors. The existing referral system to psychiatry subspecialty by general practitioners is infrequent (another indicator of the existing Knowledge, Attitude and Practice (KAP) gap). Western India has 0.4 psychiatrists and 0.002 psychologists per lakh population. Monetarily Western India is spending only $3 \%$ of its health budget on mental health. ${ }^{13}$ This makes the attempt to study the attitudes of undergraduate medical students and improvement of the attitudes if found negative an utmost necessity as these problems can only be countered by having a motivated and positive outlook towards mental illnesses. That in turn is possible only if the concerned person has a positive attitude.

It helps in bridging the gap between the high prevalence of psychiatric disorders and the low availability of current psychological care. Therefore, in this study we intend to reveal the attitudes of medical students towards psychiatry and mental illness. We also intend to evaluate the effect of clinical posting on their attitudes towards psychiatry and mental illness.

\section{MATERIALS AND METHODS}

This is a longitudinal study of a duration of of 6 months conducted with undergraduate students in their fifth semester of medical college in Western India during the academic year of 2016-2017. Each cohort of students was posted in psychiatry for a duration of 15 days. The college is associated with a tertiary care hospital in Western India.

The purpose of the study was explained to the students and the written informed consent was taken. A total of 143 students participated in the study. No one refused to give consent. A flowchart of the study method is shown in figure 1 .

The clinical posting for undergraduate students in psychiatry is first introduced in the curriculum of medical students during fifth semester of MBBS. It was their first

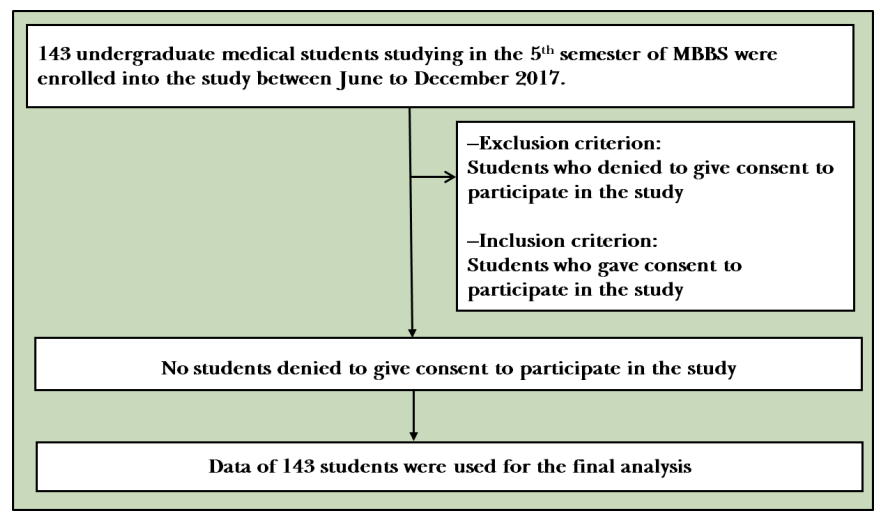

Figure 1 Flow chart of Study Method. MBBS, Bachelor of Medicine, Bachelor of Surgery. exposure to the psychiatry department and ward. The posting is in accordance with the guidelines formulated by the Medical Council of India for undergraduate medical students. The students were presented with a questionnaire in English at the beginning of their posting and at the end of it. The pro formas contained details of demographics (name initials, age, gender, academic qualification of parents, residence, religion and medical major they would like to pursue in the future) were presented to students. Personal history and family history of psychiatric illness were also included in the pro forma. A self-assessable questionnaire was filled out by the students which was based on the following scales:

1. ATP-30 scale.

2. MICA scale.

\section{ATP-30 scale}

The 30 items questionnaire ATP-30 was developed by Burra and colleagues to study attitudes towards various aspects of psychiatry on the basis of a 5-point Likert scale. This scale has multiple dimensions and measures attitudes towards mental illness, treatment, psychotherapy, psychiatric patients, psychiatric hospitals and psychiatrists, as well as psychiatric teaching. The ATP-30 consists of 30 items, of which 15 items are directed at the positive attitude towards psychiatry and the remaining 15 items are directed at the negative attitude towards psychiatry. The higher the score, the more favourable the attitude (minimum score 30=negative attitude; maximum score $150=$ positive attitude; score of $90=$ computed neutral attitude value). The ATP-30 has shown good validity and reliability and has been used in various international studies with a Cronbach's alpha of $0.831 .^{7}$

\section{MICA scale}

The medical student version of the MICA was developed and validated in 2010. It has 16 items and is rated on a 6-point Likert scale-strongly agree, agree, somewhat agree, somewhat disagree, disagree, and strongly disagree. The minimum total score is 16 and the maximum is 96 . A lower score indicates a less stigmatising attitude towards mental illness and psychiatry. The scale showed good internal consistency with a Cronbach's alpha of $0.79 .^{14}$

The clinical posting in psychiatry was for a duration of 15 days. Everyday session was for 3 hours which included a 1 hour theory lecture on various topics of psychiatry as per curriculum suggested by the Medical Council of India. ${ }^{15}$ Topics were divided among the faculty of the Department of Psychiatry including professors, associate professors, senior doctors and resident doctors in the department pursuing their postgraduation studies.

The lectures were on varied topics like history taking, mental status examination, common mental disorders, substance use disorders, psychiatric emergencies and drugs in psychiatry. Students appeared for the viva test at the end of the posting. The students were assured discretion and were told that their questionnaire would be analysed only after the results of their viva test were displayed. 


\begin{tabular}{|c|c|c|c|}
\hline & $\begin{array}{l}\text { Preclinical } \\
\text { posting }\end{array}$ & $\begin{array}{l}\text { Postclinical } \\
\text { posting }\end{array}$ & $P$ value \\
\hline \multicolumn{4}{|l|}{ ATP-30 scale } \\
\hline Total score & $89.83(11.82)$ & $93.88(9.75)$ & 0.002 \\
\hline Positive domain score & $47.89(6.89)$ & $50.39(5.40)$ & 0.001 \\
\hline Negative domain score & $41.94(6.31)$ & $43.48(6.16)$ & 0.058 \\
\hline MICA score & $53.77(7.38)$ & $51.69(8.83)$ & 0.04 \\
\hline
\end{tabular}

Data are represented as mean (SD), groups were compared using Wilcoxon paired t-test, $p<0.05$ is considered to be statistically significant.

ATP-30, Attitude Towards Psychiatry 30-item scale; MICA, Mental Illness Clinician's Attitude scale.

On each day of their posting, one theory lecture would be followed by a case presentation on the related topic. Throughout their term they were encouraged to accompany doctors in their daily ward rounds and present the number of case histories as they deem fit. To maintain consistency in teaching, in the consecutive terms the topics taught by a particular doctor to the whole cohort would remain constant. The topics discussed would also remain the same. Uniformity of the topics' contents was maintained as much as possible. Anonymity and confidentiality of data were maintained.

Qualitative data were expressed as percentages and quantitative data were expressed as mean $\pm \mathrm{SD}$. The statistical analysis was done with GraphPad, InStat V.3.06 (San Diego, California, USA). Proportions of participants were compared using $\chi^{2}$ test while scores of ATP-30 scale and MICA scale were compared using Wilcoxon signed-rank test. A p value $<0.05$ was considered statistically significant.

Table 2 Individual items of ATP-30 questionnaire which showed significant improvement following psychiatry clinical posting $(n=143)$

\begin{tabular}{|c|c|c|c|c|}
\hline Questions & $\begin{array}{l}\text { Response of } \\
\text { students }\end{array}$ & $\begin{array}{l}\text { Preclinical } \\
\text { posting (\% of } \\
\text { students) }\end{array}$ & $\begin{array}{l}\text { Postclinical } \\
\text { posting (\% of } \\
\text { students) }\end{array}$ & $P$ value \\
\hline \multirow[t]{3}{*}{ I would like to be a psychiatrist. } & Agree & 27.97 & 49.65 & \multirow[t]{3}{*}{$<0.001$} \\
\hline & Neutral & 42.65 & 36.36 & \\
\hline & Disagree & 29.37 & 13.99 & \\
\hline \multirow[t]{3}{*}{ Psychiatry is a respected branch of medicine. } & Agree & 69.23 & 86.71 & \multirow[t]{3}{*}{$<0.001$} \\
\hline & Neutral & 18.88 & 9.09 & \\
\hline & Disagree & 11.89 & 4.16 & \\
\hline \multirow{3}{*}{$\begin{array}{l}\text { With the forms of therapy now available, most psychiatric } \\
\text { patients improve. }\end{array}$} & Agree & 65.73 & 76.22 & \multirow[t]{3}{*}{0.01} \\
\hline & Neutral & 24.48 & 11.18 & \\
\hline & Disagree & 9.79 & 12.58 & \\
\hline \multirow{3}{*}{$\begin{array}{l}\text { There is very little that psychiatrists can do for their } \\
\text { patients. }\end{array}$} & Agree & 10.50 & 26.57 & \multirow[t]{3}{*}{0.016} \\
\hline & Neutral & 15.38 & 9.79 & \\
\hline & Disagree & 74.12 & 63.63 & \\
\hline \multirow{3}{*}{$\begin{array}{l}\text { Psychiatry is so unscientific that even psychiatrists can't } \\
\text { agree as to what its basic applied sciences are. }\end{array}$} & Agree & 23.07 & 27.97 & \multirow[t]{3}{*}{0.02} \\
\hline & Neutral & 33.56 & 19.58 & \\
\hline & Disagree & 43.35 & 52.45 & \\
\hline \multirow{3}{*}{$\begin{array}{l}\text { In recent years psychiatric treatment has become quite } \\
\text { effective. }\end{array}$} & Agree & 68.53 & 81.11 & \multirow[t]{3}{*}{0.04} \\
\hline & Neutral & 16.78 & 9.09 & \\
\hline & Disagree & 14.78 & 9.79 & \\
\hline \multirow{3}{*}{$\begin{array}{l}\text { Psychiatric patients are often more interesting to work with } \\
\text { than other patients. }\end{array}$} & Agree & 57.34 & 72.72 & \multirow[t]{3}{*}{0.005} \\
\hline & Neutral & 23.07 & 19.58 & \\
\hline & Disagree & 19.58 & 7.69 & \\
\hline \multirow{3}{*}{$\begin{array}{l}\text { It is quite easy for me to accept the efficacy of } \\
\text { psychotherapy. }\end{array}$} & Agree & 33.56 & 60.83 & \multirow[t]{3}{*}{$<0.001$} \\
\hline & Neutral & 39.86 & 26.57 & \\
\hline & Disagree & 26.57 & 12.58 & \\
\hline
\end{tabular}

Data are represented as percentage of students who were divided into three groups based on their responses on ATP-30 scale-agree, neutral and disagree. The groups were compared using $\chi^{2}$ test, $p<0.05$ is considered to be statistically significant.

ATP-30, Attitude Towards Psychiatry 30-item scale. 
Table 3 Individual items of MICA questionnaire which showed significant improvement following psychiatry clinical posting $(n=143)$

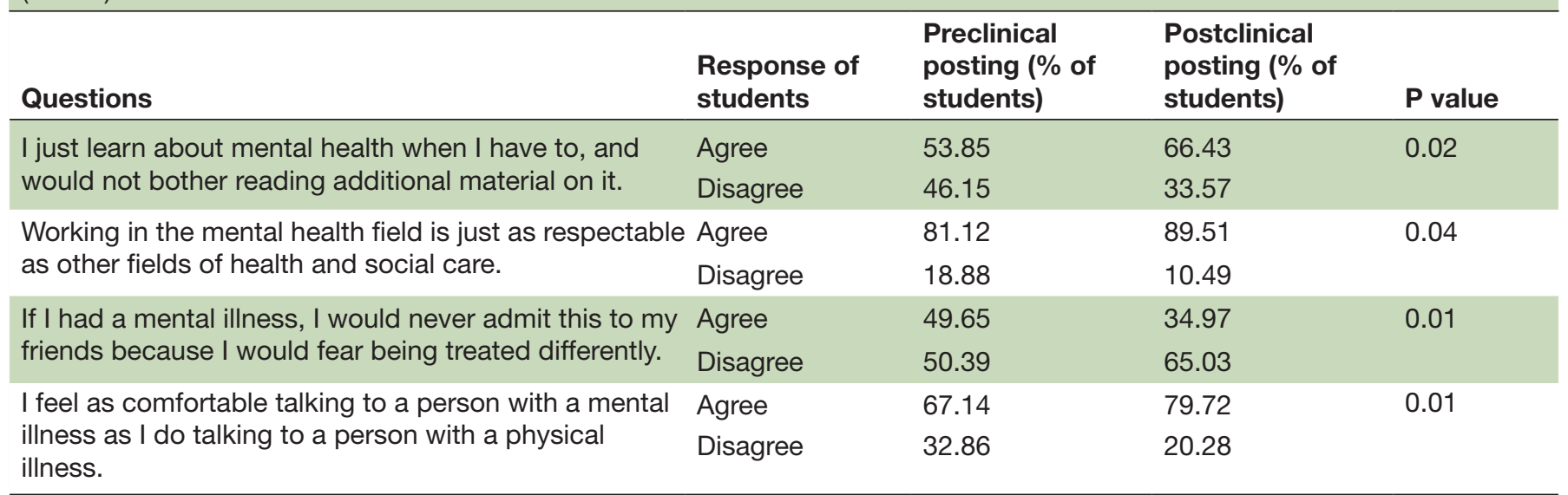

Data are represented as percentage of students who were divided into two groups based on their responses on MICA scale-agree and disagree. The groups were compared using $\chi^{2}$ test, $p<0.05$ is considered to be statistically significant.

MICA, Mental Illness Clinician's Attitude scale.

\section{RESULTS}

The study questionnaire was administered in different clinical cohorts of students in their fifth semester of medical college in Western India and responses were obtained from 143 students. Among them, 60 (41.95\%) were females and $83(58.05 \%)$ were males. The mean age of the students was 19.40 years. Forty-seven students were residing at home, while 96 students were residing at a hostel. Only one student had a history of psychiatric illness, and eight students had a family history of psychiatric illness. Mean attendance of students was 10.65 days.

Students recorded significantly higher values in total ATP-30 scores $(p=0.002)$ and MICA scores $(p=0.04)$ at the end of their clinical posting. The changes on the negative domain of ATP-30 scale were not statistically significant (table 1).

Some answers to questions on both questionnaires showed significant improvement. Those questions are demonstrated in tables 2 and 3.

As can be seen in table 4 , there were a few questions on the ATP-30 scale which showed marginal improvements in the attitude of students after clinical posting like, 'On the whole, people taking up psychiatric training are running away from participation in real medicine', 'The practice of psychotherapy basically is fraudulent since there is no strong evidence that it is effective' and 'If we listen to them, psychiatric patients are just as human as other people', with $10 \%-20 \%$ increase in the number of students either agreeing or disagreeing to the statements in terms of its direction of intent towards a positive attitude.

However, there was hardly any change in the attitude of students towards questions on the ATP-30 scale like, 'At times it is hard to think of psychiatrists as equal to other doctors' with responses being equivocal; similar number of students agreeing or disagreeing with it both preterm and post-term. Furthermore, when their response to statements like, 'If I were asked what I considered to be the three most exciting medical specialties, psychiatry would be excluded', 'Psychiatric treatment causes patients to worry too much about their symptoms' and 'Psychiatry has very little scientific information to go on', was evaluated, there were almost an equal number of students who agreed or disagreed with it, preterm and post-term; with almost no change in the number post-term (table 4).

The number of students who either agreed or disagreed with statements of the MICA scale like, 'People with a severe mental illness are dangerous more often than not' and 'If I had a mental illness, I would never admit this to my colleagues for fear of being treated differently' remained almost the same at the beginning and at the end of the term with no shift in either direction. The majority of students agreed that, 'General practitioners should not be expected to complete a thorough assessment for people with psychiatric symptoms because they can be referred to a psychiatrist' preterm; and it remained so post-term as well (table 4).

The total duration of the term was 15 days; of which a maximum of 14 days could have been attended by a student since 1 day would be a holiday owing to it being a weekend. So we tried to analyse the responses of students based on their attendance: those who attended the term for 9 days or more and those whose attendance was less than 9 days, and the results of which are demonstrated in table 5 .

As can be seen in table 5 , the mean scores of students who attended the clinical posting for 9 days or more showed statistically significant improvement on their ATP-30 score $(p=0.008)$ and but not in the MICA score $(\mathrm{p}=0.09)$.

\section{DISCUSSION}

Main findings

Our study showed that the students' attitude towards psychiatry was neutral at the beginning of the psychiatry 
Table 4 Individual items of ATP-30 and MICA questionnaire which showed positive attitude in students throughout psychiatry clinical posting $(n=143)$

\section{Questions}

Average per cent of students who agreed throughout the term

Average per cent of students who disagreed throughout the term

\section{ATP-30 scale questions}

Psychiatry is unappealing because it makes little use of medical training.

25.2

69.6

Psychiatrists talk a lot but do very little.

78.3

Psychiatric hospitals are little more than prisons.

25.9

65.9

Psychiatrists seem to talk about nothing but sex.

5.2

81.1

Psychiatric teaching increases our understanding of medical and surgical

63.6

16.1 patients.

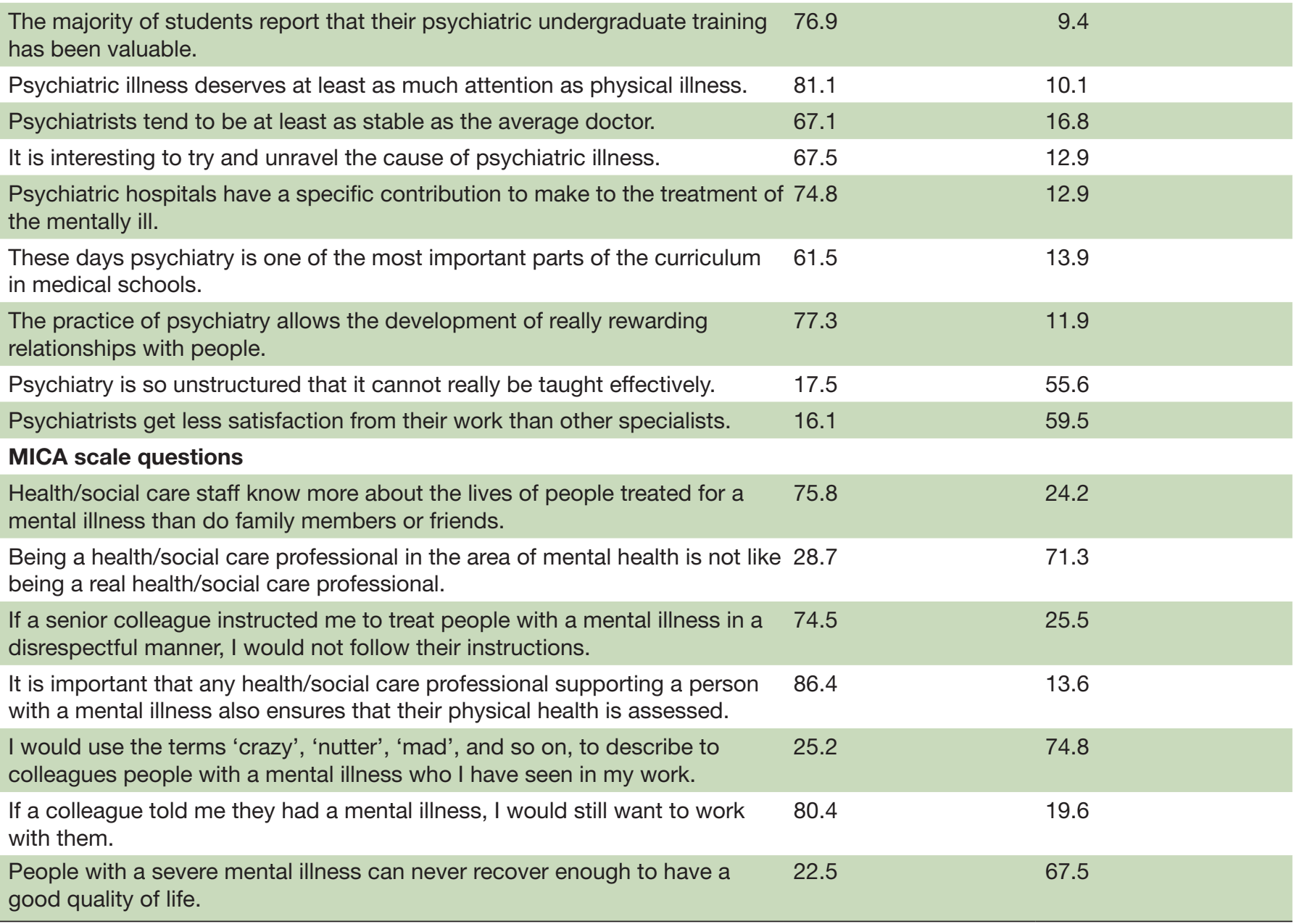

Data are represented as percentage of students who were divided into three groups based on their responses on ATP-30 and MICA scale. ATP-30, Attitude Towards Psychiatry 30-item scale; MICA, Mental Illness Clinician's Attitude scale.

clinical posting, which improved significantly on the positive domain of the ATP-30 scale and total ATP-30 score after the posting. However, the attitude on the negative domain of the ATP-30 scale improved but was not statistically significant $(\mathrm{p}=0.058)$. Our findings were consistent with previous studies. ${ }^{16-24}$ The result could be resulted from the duration of posting being 15 days. With more time maybe we could improve the negative domain scores as well, which were extrapolated in other studies. ${ }^{24} 25$
Few studies in the past showed results contradictory to ours. ${ }^{24} 26$

The change in attitude towards psychiatry and mental illness as per MICA scale was also statistically significant in our study. This is in accordance with several previous studies ${ }^{16}$ and discordant with some. ${ }^{27}$

We ventured further to evaluate the effect of psychiatry clinical posting on individual items of the scale. We found significant improvement in students' thinking to 
Table 5 Comparison of responses of students based on attendance $(n=143)$

\begin{tabular}{|c|c|c|c|c|c|c|}
\hline \multicolumn{7}{|l|}{ Attendance } \\
\hline & \multicolumn{3}{|l|}{ (<9 days) } & \multicolumn{3}{|l|}{ ( $\geq 9$ days) } \\
\hline & $\begin{array}{l}\text { Preclinical } \\
\text { posting }\end{array}$ & $\begin{array}{l}\text { Postclinical } \\
\text { posting }\end{array}$ & $P$ value & $\begin{array}{l}\text { Preclinical } \\
\text { posting }\end{array}$ & $\begin{array}{l}\text { Postclinical } \\
\text { posting }\end{array}$ & $P$ value \\
\hline ATP-30 positive domain score & $47.68(8.7)$ & $47.72(6.0)$ & 0.89 & $47.93(6.5)$ & $50.88(5.1)$ & 0.007 \\
\hline Negative domain score & $43.18(6.3)$ & $42.63(5.2)$ & 0.44 & $41.71(6.3$ & $43.63(6.3)$ & 0.01 \\
\hline Total domain score & $90.86(13.7)$ & $90.36(9.1)$ & 0.78 & $89.65(11.4)$ & $94.5(9.7)$ & 0.008 \\
\hline MICA score & $52.45(7.4)$ & $49.68(6.0)$ & 0.2 & $54.01(7.3)$ & $52.05(9.2)$ & 0.09 \\
\hline
\end{tabular}

Data are represented in mean $\pm S D$, groups were compared by Wilcoxon paired t-test, $p<0.05$ is considered to be statistically significant. The ATP-30 scale has been divided into positive and negative domains. The students were divided into two groups based on their attendance. ATP-30, Attitude Towards Psychiatry 30-item scale; MICA, Mental Illness Clinician's Attitude scale.

be a psychiatrist in future $(\mathrm{p}=0.0002)$ post-term. This was also found in other previous studies, ${ }^{16} 17232427-29$ with few exceptions. ${ }^{182}$ There was an almost $23 \%$ surge in students agreeing to think about being a psychiatrist in the future, which is an asset that needs to be shaped further to reap dividends in the long run. However, no change in response to question, 'If I were asked what I considered to be the three most exciting medical specialties, psychiatry would be excluded' post-term suggests that a positive attitude towards psychiatry does not necessarily translate to students considering it exciting as a career choice. The response to a definite question in the case record form like, 'Medical specialty interested to pursue in the future' 13 students opted for psychiatry. This number reduced to 10 students at the end of the term. Note that this response had to be handwritten and was not part of any of the scales used. We may speculate various reasons for it like negative opinions about psychiatry and mental illness in general held by clinicians from other fields of medicine affecting students, or them not finding it as financially rewarding as other specialties, students finding it tough for them to be able to show the kind of patience, empathy and compassion that a psychiatrist may hold for his patient, inability of teachers to inculcate these attributes in students, negative views about psychiatry and mental illness held by family members and perception of low prestige of psychiatry or the students' interest lying elsewhere. Similar reasons were also cited in other studies. ${ }^{1822}$ We need to dive deep into these contradictions so as to understand the relationship between various factors like classroom teaching, clinical rotation, association of students with consultants and postgraduate students in psychiatry who teach their undergraduate counterparts, role of good role models and movies in psychiatry which we feel might be useful in transforming or aiding the positive attitude post-term into seriously considering psychiatry as a career choice.

The views of students towards the positive aspects of psychiatry as a subject improved further following the term as statistically significant changes were noted in such domains on both the ATP-30 and MICA questionnaires on similarly worded or meant questions like 'Psychiatry is a respected branch of medicine', 'with the form of therapy now available, most psychiatric patients improve',
'In recent years psychiatric treatment has become quite effective', 'Psychiatric patients are often more interesting to work with than others' and 'It is quiet easy for me to accept the efficacy of Psychotherapy'. The students even disagreed more on questions like 'Psychiatry is so unscientific that even psychiatrists can't agree as to what its basic applied sciences are.' These findings were consistent across previous studies in similar items. ${ }^{1628}$ Few studies had contradictory results. ${ }^{30}$

\section{Limitations}

The sample size of 143 students was small. The study was limited to one medical college setting, so the findings cannot be generalised. At the end of the posting there were improvements in attitudes and overall perceptions of mental illness stigma. While we can conclude that the posting may have contributed towards this improvement, we cannot assume that these views will remain constant as students progress through the course. Longer term follow-up of the same cohort of students will enable attitudes to be tracked over time to determine how to maintain the gains made during the posting.

\section{Implications}

The improvement in attitude of students was directly proportional to the attendance of students. Few studies reported no change in attitude among students in a 15-day term. ${ }^{24}$ However, most studies agreed that more time spent in the psychiatry clinical term did help in producing a desired outcome. ${ }^{16} 18$ 20-25 Thus, we may concur that more time allotted to psychiatry clinical postings would indeed help produce doctors with a positive attitude towards the subject and patients. Students who either could not or did not attend the term for a sufficient number of days to produce a change in attitude could be encouraged to attend more days by giving them certain incentives to come like showing them movies on the theme of any psychiatric illness, providing them with popular books to read regarding mental illness, encouraging group discussion among students or involving the students in the teaching process. 


\section{CONCLUSION}

The students' attitude towards psychiatry was neutral at the beginning of the psychiatry clinical posting, which improved significantly at the end of the posting on both scales applied: ATP-30 and MICA. The students became more positive towards the subject and mental illness in general. We found significant improvement in students' thinking about being a psychiatrist in the future postterm. The improvement in attitude of students was directly proportional to their attendance.

Contributors $\mathrm{RD}$ is responsible for the overall content as a guarantor.

Funding The authors have not declared a specific grant for this research from any funding agency in the public, commercial or not-for-profit sectors.

Competing interests None declared.

Patient consent for publication Not required.

Ethics approval Prior permission to conduct the study was taken from the concerned ethics committee: Institutional Review Board (Human Ethics Committee), Government Medical College, Bhavnagar (IRB00008091, ECR/557/Inst/GJ/2014).

Provenance and peer review Not commissioned; externally peer reviewed. Data sharing statement No additional data are available.

Open access This is an open access article distributed in accordance with the Creative Commons Attribution Non Commercial (CC BY-NC 4.0) license, which permits others to distribute, remix, adapt, build upon this work non-commercially, and license their derivative works on different terms, provided the original work is properly cited, appropriate credit is given, any changes made indicated, and the use is non-commercial. See: http://creativecommons.org/licenses/by-nc/4.0/.

\section{REFERENCES}

1 Demyttenaere K, Bruffaerts R, Posada-Villa J, et al. Prevalence, severity, and unmet need for treatment of mental disorders in the World Health organization world mental health surveys. JAMA 2004;291:2581-90.

2 Alonso J, Angermeyer MC, Bernert S, et al. Prevalence of mental disorders in Europe: results from the European study of the epidemiology of mental disorders (ESEMeD) project. Acta Psychiatr Scand Suppl 2004;(420):21-7.

3 Evans S, Banerjee S, Leese M, et al. The impact of mental illness on quality of life: a comparison of severe mental illness, common mental disorder and healthy population samples. Qual Life Res 2007;16:17-29.

4 Rüsch N, Angermeyer MC, Corrigan PW. Mental illness stigma: concepts, consequences, and initiatives to reduce stigma. Eur Psychiatry 2005;20:529-39.

5 Lyons Z. Attitudes of medical students toward psychiatry and psychiatry as a career: a systematic review. Acad Psychiatry 2013;37:150-7.

6 Rezler AG. Methods of attitude assessment for medical teachers. Med Educ 1976;10:43-51.

7 Burra P, Kalin R, Leichner P, et al. The ATP 30-a scale for measuring medical students' attitudes to psychiatry. Med Educ 1982;16:31-8.

8 Katschnig H. Are psychiatrists an endangered species? Observations on internal and external challenges to the profession. World Psychiatry 2010;9:21-8.
9 Cutler JL, Harding KJ, Mozian SA, et al. Discrediting the notion "working with 'crazies' will make you 'crazy' ": addressing stigma and enhancing empathy in medical student education. Adv Health Sci Educ Theory Pract 2009;14:487-502.

10 Gask L, Coskun B, Baron DA. Teaching psychiatry: putting theory into practice. John Wiley \& Sons, 2011.

11 Brown TM, Addie K, Eagles JM. Recruitment into psychiatry: views of consultants in Scotland. Psychiatr Bull 2007;31:411-3.

12 Roberts LW, Bandstra BS. Addressing stigma to strengthen psychiatric education. Acad Psychiatry 2012;36:347-50.

13 Patel V, Xiao S, Chen $\mathrm{H}$, et al. The magnitude of and health system responses to the mental health treatment gap in adults in India and China. Lancet 2016;388:3074-84.

14 Kassam A, Glozier N, Leese M, et al. Development and responsiveness of a scale to measure clinicians' attitudes to people with mental illness (medical student version). Acta Psychiatr Scand 2010;122:153-61.

15 Kallivayalil R. The importance of psychiatry in undergraduate medical education in India. Indian J Psychiatry 2012;54.

16 Sarker MR, Khan MZR, Jahan N, et al. Attitudes towards psychiatry among undergraduate medical students. Bangladesh Journal of Psychiatry;28:45-9.

17 Mottaghipour Y, Noroozi AR, Samimi M. The effect of psychiatric clerkship on fifth year medical students' attitudes toward psychiatry and their intention to pursue psychiatry as a career. Iranian Journal of Psychiatry 2005;1:98-103.

18 Sarhan A, Alkhiri A, Maqadmi A, et al. Medical students attitude toward psychiatry in Umm al-qura university: a cross-sectional study. Int J Adv Res 2017;5:1359-68.

19 Qubtan AA, Lawati JA, Alawi MA, et al. Attitude of medical students at Sultan Qaboos university toward Psychiatryl. Int J Pub health safe 2015;1.

20 Risal A, Sharma PP, Sanjel S. Attitude toward mental illness and psychiatry among the medical students and interns in a medical college. JNMA J Nepal Med Assoc 2013;52:322-31.

21 Connaughton J, Gibson W. Physiotherapy students' attitudes toward psychiatry and mental health: a cross-sectional study. Physiother Can 2016;68:172-8.

22 Olotu OS, Osahon PO. The effects of a clinical Posting in psychiatry on the beliefs and attitudes of medical students towards the discipline. Nigerian Journal of Psychiatry 2001;5:305-13.

23 Rodrigo A, Wijesinghe C, Kuruppuarachchi K. Changes in attitudes toward psychiatry with introduction of a new curriculum: experiences of a Sri Lankan medical school. Sri Lanka J. Psyc. 2012;3:14-16.

24 Rajagopalan M, Kuruvilla K. Medical students' attitudes towards psychiatry: effect of a two week Posting. Indian J Psychiatry 1994;36.

25 Reddy S, Reddy P, Mishra K. Impact of duration of psychiatry rotation on medical interns' attitude towards psychiatry. Open J Psychiatry Allied Sci 2017;8:18-23.

26 Alpaslan A, Kocak U, Coskun K, et al. Attitude towards psychiatry and its possible association with alexithymia among medical students. Journal of Mood Disorders 2015;5:157-63.

27 Lyons Z, Janca A. Impact of a psychiatry clerkship on stigma, attitudes towards psychiatry, and psychiatry as a career choice. BMC Med Educ 2015;15.

28 Bulbena A, Pailhez G, Coll J, et al. Changes in the attitudes towards psychiatry among Spanish medical students during training in psychiatry. Eur. J. Psychiat. 2005;19:79-87.

29 Jyothi NU, Bollu M, Ali SF, et al. Mounika S. A questionnaire survey on student's attitudes towards individuals with mental illness. Journal of Pharmaceutical Sciences and Research 2015;7.

30 Parikh NC, Sharma PS, Chaudhary PJ, et al. Study of attitude of interns toward psychiatry: a survey of a tertiary level hospital in Ahmedabad. Ind Psychiatry J 2014;23.

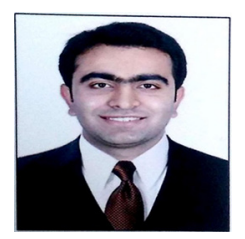

Dr Rishi Desai obtained his MBBS degree from Govt Medical College, Bhavnagar, India and is currently pursuing his post graduation in Psychiatry at Govt Medical College, Bhavnagar, India. His research interest includes Substance Use Disorder and Psychosexual Disorders. 